\title{
INFLUÊNCIA DA MINIESTAQUIA SERIADA NO VIGOR DE MINICEPAS DE CLONES DE Eucalyptus grandis ${ }^{1}$
}

\author{
Ivar Wendling ${ }^{2}$, Aloisio Xavier ${ }^{3}$ e Haroldo Nogueira de Paiva ${ }^{3}$
}

\begin{abstract}
RESUMO - Neste estudo objetivou-se avaliar a influência dos subcultivos de miniestaquia seriada na capacidade de produção, vigor e sobrevivência das minicepas de quatro clones de Eucalyptus grandis, nas sucessivas coletas de miniestacas. O jardim miniclonal foi localizado em ambiente coberto por plástico transparente e conduzido em sistema de hidroponia em calhetão. A sobrevivência das minicepas foi superior a $96 \%$ após as sete coletas de brotações, para todos os clones e subcultivos. Em relação à produtividade e ao vigor das minicepas, ocorreram variações entre os clones e as coletas estudadas e, de modo geral, a miniestaquia seriada não proporcionou efeitos significativos.
\end{abstract}

Palavras-chave: Silvicultura clonal, jardim clonal, rejuvenescimento e propagação clonal.

\section{INFLUENCE OF SERIAL MINICUTTING TECHNIQUE ON THE VIGOR OF Eucalyptus grandis MINISTUMPS}

\begin{abstract}
The objective of this study was to evaluate the influence of serial minicutting technique on the production capacity, vigor and survival of Eucalyptus grandis ministumps in successive minicutting collections. The miniclonal garden was located in an environment covered by transparent plastic, under a hydroponic system. The survival of ministumps was superior to $96 \%$ after the seven collections were conducted for all the clones and subcultures. Regarding ministump productivity and vigor, variations were observed among clones and collections and the serial minicutting technique did not provide significant effects, overall.
\end{abstract}

Key words: $\quad$ Clonal forestry, miniclonal gardem, rejuvenation and clonal propagation.

\section{INTRODUÇÃO}

A propagação vegetativa de Eucalyptus no Brasil passou por inúmeras modificações, tendo início com a técnica de estaquia, implementada em escala comercial no final da década de 70 (Ikemori, 1975). Atualmente, a técnica de miniestaquia vem sendo adotada na maioria das médias e grandes empresas florestais brasileiras.

Inicialmente, na miniestaquia, as minicepas eram conduzidas em tubetes com fertirrigação via sistema de irrigação aérea. Hoje têm-se a hidroponia em tubetes com fornecimento de solução nutritiva por subirrigação (Silva, 2001; Titon, 2001;), em vasos (Fernandes, 1999; Higashi et al., 2002), por condução em calhetão ou hidroponia em sistema de calhetão (Higashi et al., 2002), além de outros.

Na hidroponia em tubetes com fornecimento de solução nutritiva por subirrigação, a irrigação e a nutrição mineral são fornecidas através de um sistema automatizado de fertirrigação por capilaridade, de modo que somente o sistema radicular permaneça em contato com a solução nutritiva (Titon, 2001). O sistema calhetão se

1 Recebido para publicação em 17.5.2002.

Aceito para publicação em 9.9.2003.

2 Engenheiro Florestal, D.S., Pesquisador Embrapa Florestas, 83411-000 Colombo-PR. ${ }^{3}$ Professor do Departamento de Engenharia Florestal da Universidade Federal de Viçosa - UFV, 36571-000 Viçosa-MG. 
baseia na condução das minicepas em calhetões de cimento-amianto, contendo areia de granulometria grossa, onde são cultivadas as minicepas em espaçamentos definidos, geralmente em torno de 100 minicepas por metro quadrado (Wendling, 2002).

Durante a passagem do estado juvenil para o adulto, as plantas sofrem inúmeras modificações, podendo resultar em mudanças no seu comportamento, como o hábito e o vigor de crescimento. O crescimento plagiotrópico, por exemplo, refere-se à situação em que as plantas formadas por propagação vegetativa assumem um crescimento desviado da vertical (ortotropia) e continuam seu crescimento de forma similar a um galho lateral, ou seja, crescimento plagiotrópico (Zobel \& Talbert,1984).

Segundo dados experimentais de Greenwood \& Hutchison (1993), árvores originadas por enxertia ou enraizamento de estacas de propágulos juvenis de Tsuga canadensis e Pinus taeda tendem a exibir maior número de brotações por unidade de área, o que também está de acordo com os resultados de Parker et al. (1998), bem como maior tendência ao crescimento ortotrópico do que aqueles de propágulos maduros.

Não há estudos referentes aos efeitos de diferentes gradientes de maturidade dos propágulos utilizados na propagação para as espécies do gênero Eucalyptus. Porém, em nível de viveiro e campo, podem ser observados plantas com características que lembram o crescimento plagiotrópico.

O rejuvenescimento de plantas tem recebido especial atenção nas últimas décadas, principalmente pelas inúmeras aplicações desta técnica na melhoria dos processos de produção florestal, passando pela fase de produção das mudas até a condução de povoamentos mais produtivos, mais uniformes e de melhores características dos produtos finais.

Entre os principais métodos de rejuvenescimento e, ou, manutenção da juvenilidade de plantas adotados, podem ser citadas a propagação vegetativa seriada e as podas sucessivas (Hackett, 1987; Eldridge et al., 1994).

O efeito da estaquia seriada sobre o rejuvenescimento em Eucalyptus spp., resultando em possíveis efeitos positivos sobre o enraizamento, foi citado por Eldridge et al. (1994) e em alguns trabalhos desenvolvidos nesta linha por Clair et al. (1985), para Picea abies. Entretanto, ainda há carência de informações consistentes em relação aos aspectos relacionados à capacidade de

R. Árvore, Viçosa-MG, v.27, n.5, p.611-618, 2003 propagação vegetativa, principalmente dos efeitos de métodos de rejuvenescimento no comportamento das plantas-matrizes (cepas) no que tange a sua produtividade, a seu vigor e à sua sobrevivência.

Na clonagem de Eucalyptus, o rejuvenescimento pela miniestaquia seriada pode vir a ser eficiente para clones menos exigentes, servindo, desta forma, como alternativa às técnicas mais sofisticadas de rejuvenescimento, como a micropropagação. A implantação de jardins miniclonais com minicepas rejuvenescidas poderia permitir a obtenção de maior vigor e qualidade dos brotos produzidos para propagação clonal por miniestaquia, principalmente em relação ao seu maior potencial de enraizamento, visto seu maior grau de juvenilidade.

Assim, no presente estudo, objetivou-se avaliar a influência da miniestaquia seriada na propagação vegetativa de quatro clones de Eucalyptus grandis W.Hill ex Maiden quanto à capacidade de produção, ao vigor e à sobrevivência das minicepas nas sucessivas coletas de miniestacas.

\section{MATERIAL E MÉTODOS}

O experimento foi conduzido na Empresa Celulose Nipo-Brasileira S.A. - CENIBRA, sediada no município de Belo Oriente-MG. Foram utilizados quatro clones comerciais de Eucalyptus grandis (CC10, CC12, CC14 e CC15), selecionados para celulose em uma população de procedência de Rio Claro-SP e propagados vegetativamente a partir da técnica de estaquia convencional. Os clones se encontravam em jardim clonal comercial de campo, de onde foram resgatados pela técnica de estaquia convencional, com manejo e nutrição de acordo com os procedimentos adotados pela empresa CENIBRA.

As miniestacas foram obtidas a partir de minicepas formadas de mudas produzidas pelo processo de estaquia convencional (jardim 0), as quais foram enraizadas em casa de vegetação sem a aplicação de reguladores de crescimento. As miniestacas permaneceram em casa de vegetação por 25 dias, em casa de sombra por mais 10 dias e, posteriormente, em rustificação a pleno sol, onde, após 20 dias, foram podadas para formação das minicepas do subcultivo 1.

As mudas formadas a partir das miniestacas enraizadas do subcultivo 1, ao atingirem de 10 a $12 \mathrm{~cm}$ de altura (em torno dos 60 dias de idade), tiveram seu ápice podado a uma altura de $6-8 \mathrm{~cm}$ da base, formando as minicepas 
do subcultivo 2, que, após 20 - 30 dias, forneceram as brotações (miniestacas). As minicepas do subcultivo 2, de forma similar àquelas do subcultivo 1 , forneceram novas miniestacas para formação do jardim miniclonal do subcultivo 3, e assim sucessivamente, até o subcultivo 7. Assim, foram formados sete jardins miniclonais $(0,1$, $2,3,4,5$ e 6 ), ou seja, sete subcultivos de miniestaquia $(1,2,3,4,5,6$ e 7$)$.

O jardim miniclonal foi localizado em ambiente coberto por plástico transparente e conduzido em sistema de hidroponia em calhetão, com aproximadamente 100 minicepas por metro quadrado, sendo cada clone representado por 130 minicepas por subcultivo. Em períodos regulares de cinco a dez dias, as minicepas receberam podas seletivas para coleta de miniestacas, que foram mantidas durante toda fase experimental, visando o manejo adequado das minicepas nos jardins miniclonais.

Foram formados sete jardins miniclonais (JM0, JM1, JM2, JM3, JM4, JM5 e JM6), ou seja, sete subcultivos de rejuvenescimento $(0,1,2,3,4,5$ e 6$)$, conforme Figura 1.

Uma vez formados os jardins miniclonais dos sete subcultivos, conforme citado anteriormente, foram coletadas, simultaneamente, miniestacas dos jardins de subcultivos zero (jardim formado de mudas originárias de estacas), 2, 4 e 6, após a sua formação ter sido completada. Desses jardins, foram enraizadas miniestacas e formadas as minicepas para os jardins utilizados na experimentação (jardim miniclonal de subcultivos 1, 3,5 e 7), os quais forneceram as miniestacas para os testes comparativos.
Esse procedimento, além de facilitar a operacionalização dos testes comparativos entre os subcultivos, objetivo do presente estudo, visou também a padronização da idade das minicepas de todos os subcultivos, para posterior coleta de miniestacas.

Para cada clone, subcultivo e coleta, foram avaliados a sobrevivência, a capacidade produtiva e o vigor vegetativo das minicepas. Para esta última avaliação, foi realizada poda drástica de todas as brotações acima de $0,5 \mathrm{~cm}$ de comprimento, onde se efetuaram medições aos $3,6,9$ e 12 dias, adotando-se três classes de comprimento (classe 1: de 0,5 a 2,0 cm; classe 2: de 2,1 a 4,0 cm; e classe 3: $>4,0 \mathrm{~cm}$ ). Ao término dos 12 dias foi avaliado o peso da matéria seca das brotações.

O delineamento experimental utilizado foi o inteiramente casualizado, em arranjo fatorial $4 \times 4$ (quatro subcultivos e quatro clones) e cinco repetições. Os dados resultantes foram submetidos à análise de variância, aplicando-se para a produtividade do jardim miniclonal testes de médias (Scott-Knott e Tukey), a 5\% de probabilidade.

\section{3 . RESULTADOS E DISCUSSÕES}

A sobrevivência das minicepas dos jardins miniclonais foi superior a $96 \%$ após sete coletas de miniestacas, para todos os clones e subcultivos, o que evidencia a capacidade de propagação vegetativa do material genético e a eficiência do sistema de jardim clonal adotado na experimentação.

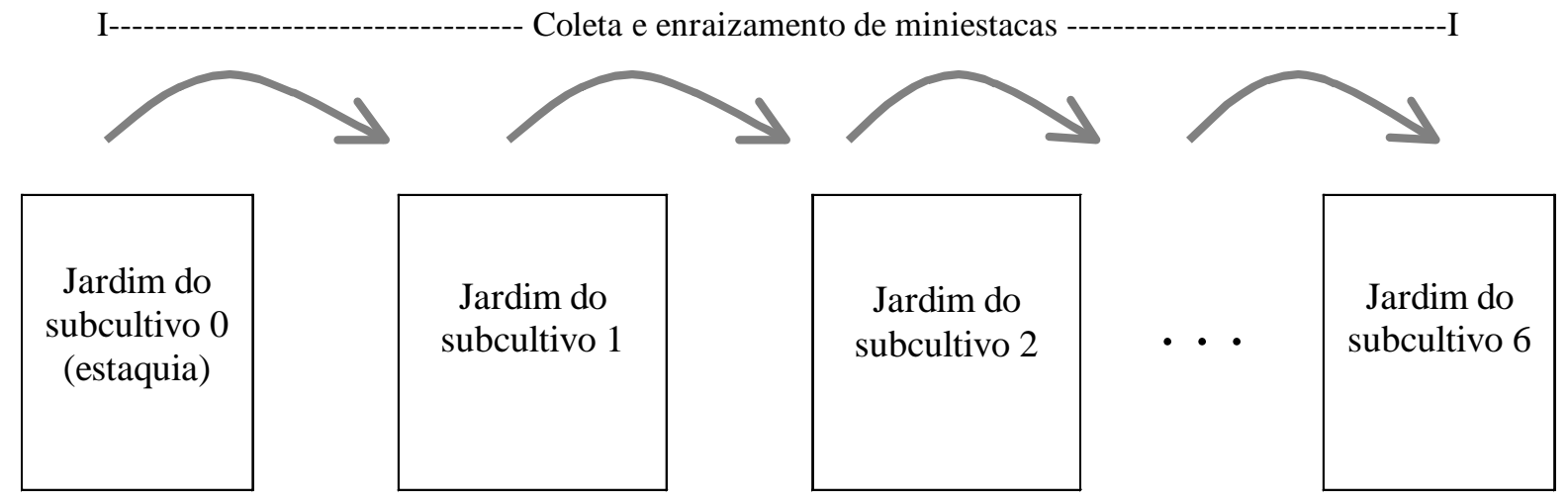

Figura 1 - Fluxograma adotado para o rejuvenescimento por miniestaquia seriada e formação dos jardins miniclonais. Figure 1 - Flowchart adopted for rejuvenation by serial minicutting technique and formation of miniclonal gardens. 
Os resultados da análise de variância para a característica de produção de miniestacas por minicepa demonstram efeito significativo, tanto em relação aos diferentes clones, quanto aos subcultivos. O coeficiente de variação experimental encontrado para esta característica foi de $14,8 \%$, o que indica boa precisão experimental.

Com base na Figura 2, constata-se que as minicepas dos subcultivos maiores, principalmente do 7, apresentaram tendência de diminuição na produção de miniestacas, para todos os clones estudados, embora tenha ocorrido comportamento diferenciado em relação às coletas, o que indica um possível maior grau de juvenilidade dos subcultivos maiores, resultando em miniestacas maiores e mais vigorosas, com tendências ao crescimento ortotrópico, ou seja, maior crescimento vegetativo em altura e menor número de brotos laterais. Estes resultados corroboram com os encontrados por Titon (2001), para Eucalyptus, que constatou a persistência da dominância apical em mudas com maior grau de juvenilidade.

No que tange às sete coletas de miniestacas, percebese um comportamento variável, sendo as de número 5, 6 e 7 de maior produção (de 4,4 a 9,7 miniestacas por minicepa por coleta) e as de 1,2 e 3 de menor produção (2,0 a 6,0 miniestacas por minicepa por coleta), variável em função do clone, porém sem apresentação de uma tendência clara, de forma similar aos resultados encontrados por Titon (2001). Este comportamento pode ser em função da necessidade de adaptação inicial das minicepas ao ambiente de hidroponia, bem como à quebra de dominância apical após a poda. Portanto, após algumas coletas, as gemas dormentes tornaram-se reativas, resultando em maior estímulo ao crescimento, assim como o melhor ajuste do manejo do jardim com o decorrer das coletas também pode ter influenciado este comportamento.

Em relação aos quatro clones estudados, detecta-se a superioridade do clone CC15 quanto à produção de miniestacas por minicepa.

Com base no Quadro 1 constata-se que, na maioria das vezes, o vigor dos subcultivos menores (1 e 3 ) foi significativamente superior ao dos demais, principalmente nas classes de tamanho 1 e 2 . Já na classe de maior tamanho (classe 3), a tendência de superioridade dos menores subcultivos já não é mais observada mais com

R. Árvore, Viçosa-MG, v.27, n.5, p.611-618, 2003 tanta clareza. Estas constatações indicam um possível efeito de rejuvenescimento, uma vez que, em geral, nos maiores subcultivos, principalmente no de número 7 , o vigor se igualou mais aos das classes de menor tamanho (classes 1 e 2).

O fato de o vigor das minicepas dos maiores subcultivos não se mostrar superior ao dos menores subcultivos pode estar relacionado ao menor vigor inicial destas em relação ao daquelas. Além disto, segundo Hackett \& Murray (1993) e Greenwood (1992), não é surpresa que algumas características relacionadas à maturação sejam mais facilmente rejuvenescidas que outras e que a facilidade de rejuvenescimento de determinada característica pode se modificar com a intensidade de tratamento particular ou com a duração, podendo influenciar uma ou várias características, porém não todas, o que leva a confirmar a teoria de que o rejuvenescimento ocorre em termos relativos, e não absolutos (Hackett \& Murray, 1993). Assim, pode-se atribuir o fato de as minicepas do subcultivo 7 não terem maior vigor a um possível não-rejuvenescimento nessa característica particular.

Quando se analisa o número de brotações acima de $0,5 \mathrm{~cm}$ (total), constata-se a hipótese de maior brotação de minicepas dos menores subcultivos, o que concorda com os resultados de produção de miniestacas (Figura 2). Mesmo comportamento pode ser visualizado quando se comparam as médias dos diferentes subcultivos, sendo aquelas do subcultivo 7 significativamente inferiores à dos demais subcultivos.

Na Figura 3 é apresentado o peso da matéria seca da parte aérea (PMS), referente à coleta de todas as brotações acima de $0,5 \mathrm{~cm}$ de comprimento, realizada aos 12 dias após a poda drástica. Percebe-se que, entre os subcultivos estudados, houve diferença significativa somente para o clone CC10, sendo o subcultivo 7 o de menor matéria seca, porém não variando significativamente dos subcultivos 1 e 5 .

Em relação aos quatro clones estudados, observa-se a superioridade do clone CC12 (com média de 487,1 mg) em relação aos demais, seguido pelo clone CC10 (com média de 397,2 mg), pelo clone CC14 (com média de $332,2 \mathrm{mg}$ ) e pelo clone CC15 (com média de 312,4 mg). Porém esta diferença somente é significativa em termos de superioridade para os clones CC12 e CC10, com exceção do subcultivo 7, em relação aos clones CC14 e CC15. 


\section{Clone CC10}

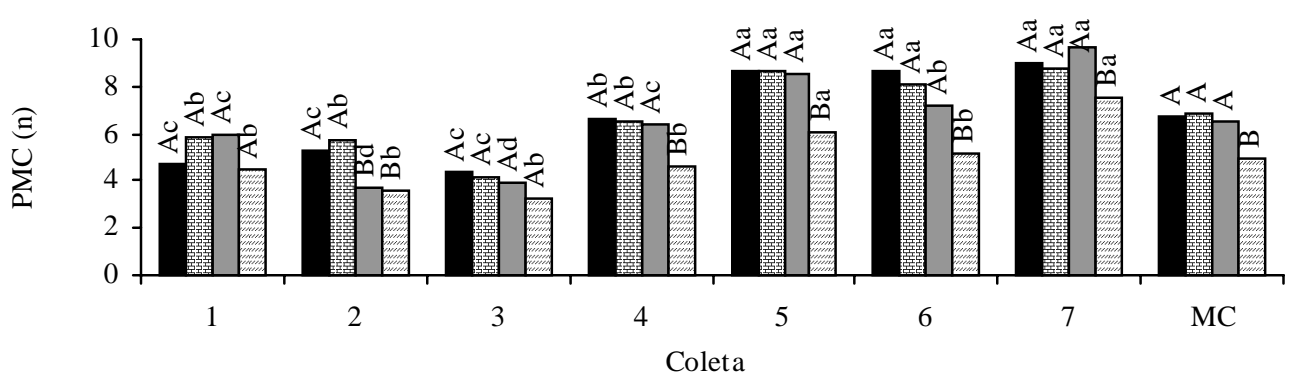

Sub 1

圖 Sub 3

$\square$ Sub 5

Sub 7

\section{Clone CC15}

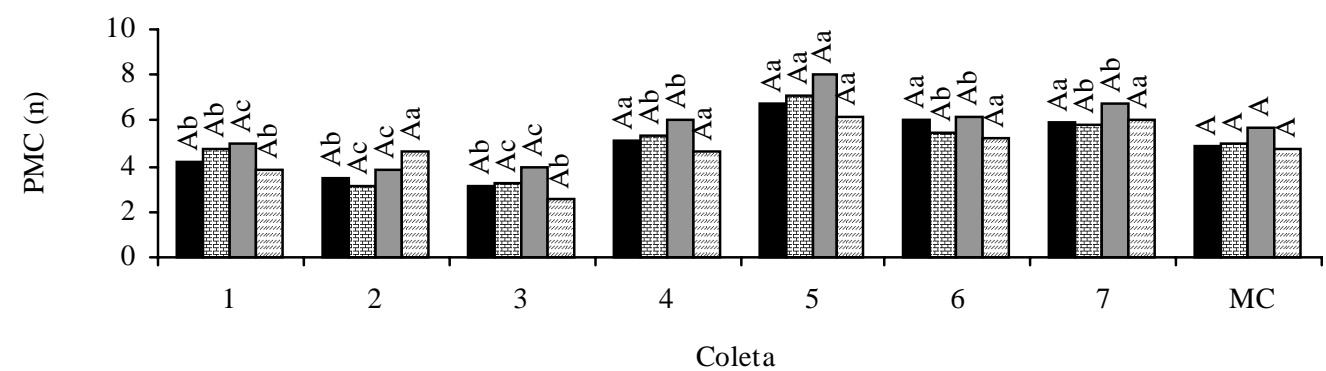

Sub 1

團Sub 3

$\square$ Sub 5

圆 Sub 7

\section{Clone CC14}

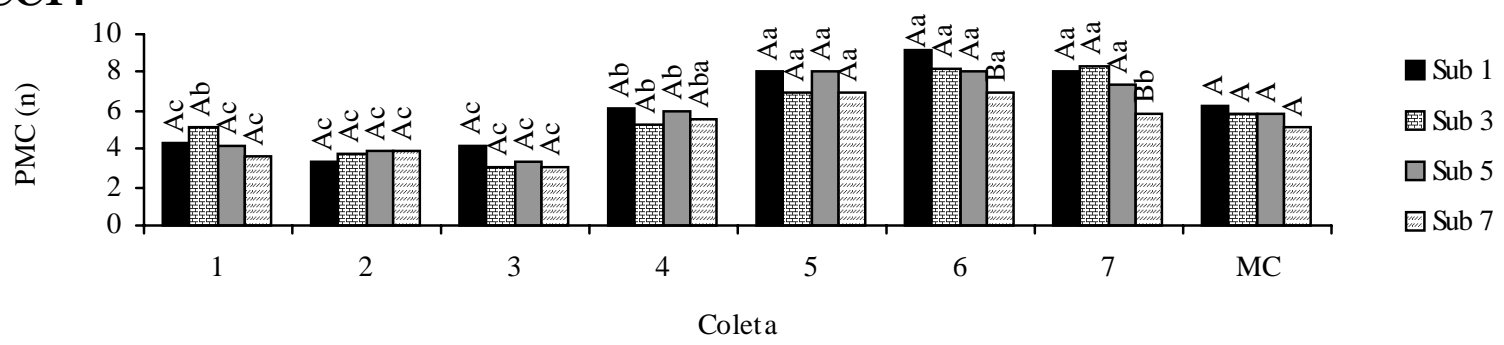

\section{Clone CC12}

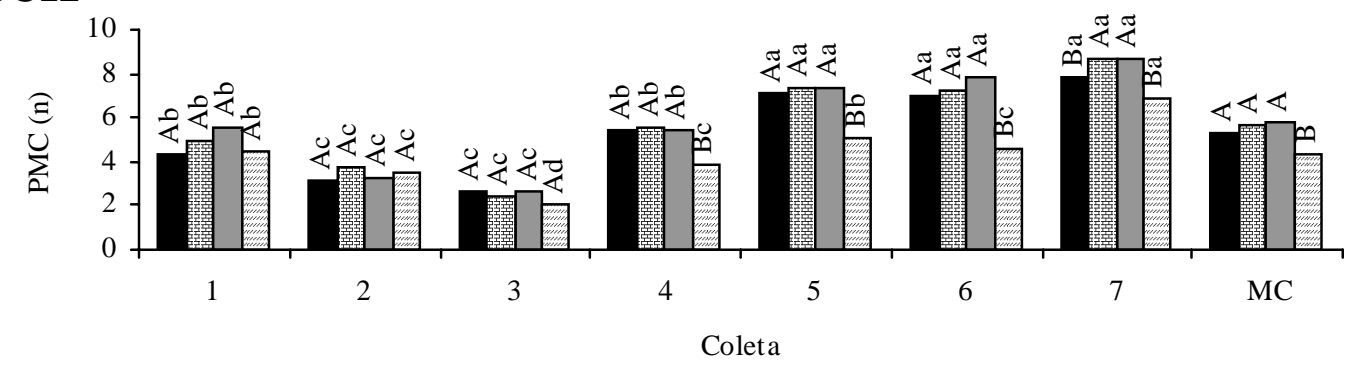

Figura 2 - Produção de miniestacas por minicepa por coleta (PMC) dos quatro subcultivos de miniestaquia seriada (Sub) em função do número de coletas efetuadas no jardim miniclonal, para os quatro clones de Eucalyptus grandis, e média das sete coletas (MC). As médias seguidas de uma mesma letra maiúscula dentro de uma mesma coleta e as seguidas de uma mesma letra minúscula entre as coletas, dentro de cada subcultivo, respectivamente, não diferem entre si pelo teste de agrupamento de Scott-Knott, a 5\% de probabilidade.

Figure 2-Minicutting production per ministump (PMC) of the four serial minicuttings technique subcultures (Sub) in function of the collection number in the miniclonal garden, for the four Eucalyptus grandis clones and the average of the seven collections $(M C)$. 


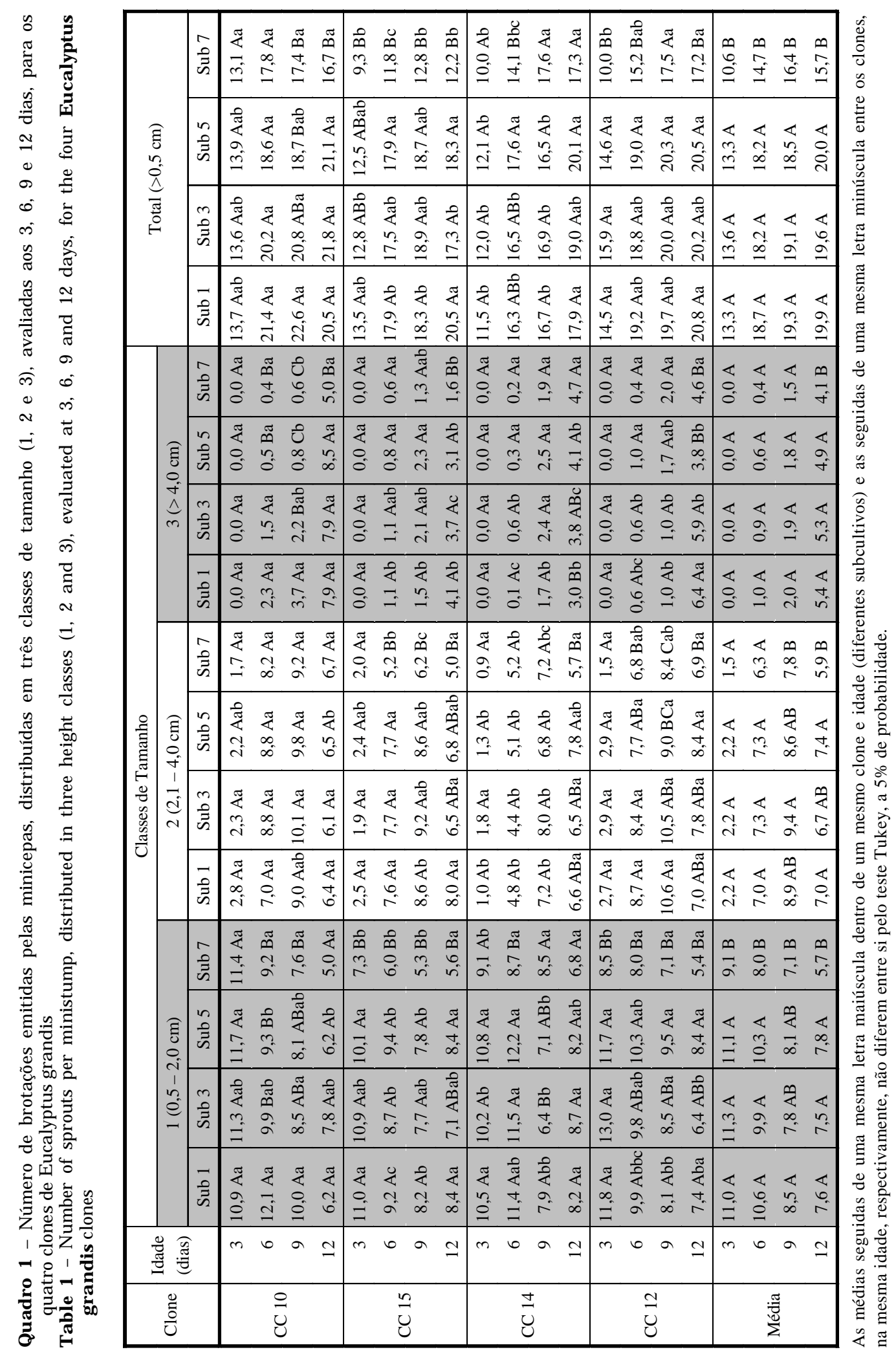




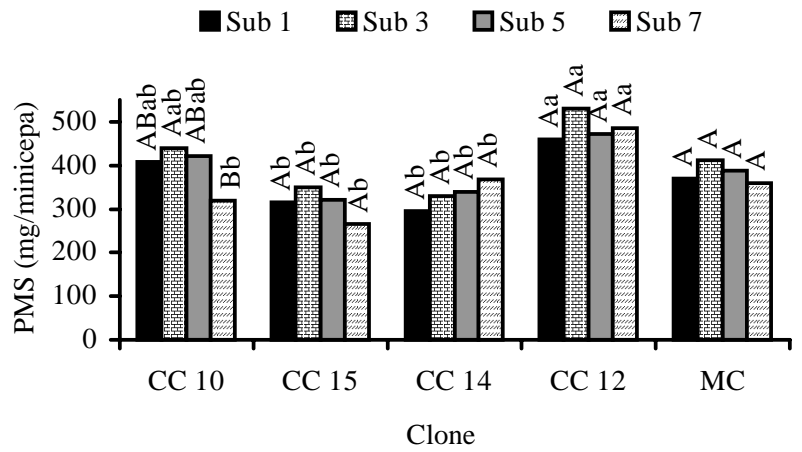

Médias seguidas de uma mesma letra maiúscula dentro de cada clone, entre os subcultivos, e de uma mesma letra minúscula entre os clones, dentro de cada subcultivo, não diferem entre si pelo teste de Tukey, a $5 \%$ de probabilidade.

Figura 3 - Peso de matéria seca (PMS) das brotações produzidas pelas minicepas coletadas no final de 12 dias, para os quatro subcultivos e os quatro clones, e média dos clones (MC).

Figure 3 - Dry weight (PMS) of the sprouts produced by the ministumps collected after 12 days, for the four serial minicutting subcultures, four clones and clone average (MC).

De modo geral, pode-se concluir que os subcultivos não resultaram em aumento de vigor das minicepas, mostrando até uma certa tendência de redução deste com o aumento dos subcultivos, o que pode estar relacionado à maior tendência ao crescimento ortotrópico, conforme citado por Parker et al. (1998), resultando em menor número e peso de matéria seca de brotos.

Segundo Hackett \& Murray (1993), as características relacionadas à maturação são reversíveis, porém não apresentam o mesmo grau de facilidade, que, para determinada característica, é variável de acordo com o grau de juvenilidade do clone. Assim, para observação de mudanças mais drásticas no vigor das minicepas, poderia ser avaliada em novos trabalhos a utilização de propágulos oriundos de plantas com maior idade ontogenética, ou ainda que estas características não são influenciadas pelo gradiente de juvenilidade dos propágulos vegetativos.

Em termos de viveiros comerciais para propagação clonal de Eucalyptus, a propagação vegetativa seriada já é adotada em alguns casos, como nas condições em que o número de plantas-matrizes é insuficiente, tornandose necessário o seu subcultivo para atingir um número satisfatório de matrizes. Com base nesses aspectos, constatou-se que a estaquia seriada e, mais recentemente, a miniestaquia seriada podem estar resultando em efeitos sobre o vigor dessas plantas.

\section{CONCLUSÕES}

O sistema de cultivo das minicepas adotado permitiu a obtenção de altos índices de sobrevivência, independentemente do genótipo, do subcultivo e, ou, da coleta, o que demonstra a sua adequabilidade à propagação clonal de Eucalyptus; o grau de rejuvenescimento foi variável em função das características e dos clones avaliados; e os subcultivos de miniestaquia seriada, de modo geral, não proporcionaram efeito significativo em relação às características de vigor das minicepas avaliadas.

\section{AGRADECIMENTO}

À Celulose Nipo-Brasileira S.A. - CENIBRA, pela disponibilização do material experimental e pelo apoio orçamentário e estrutural na condução das pesquisas.

À Fundação de Amparo a Pesquisa do Estado de Minas Gerais - FAPEMIG - e à Federação das Indústrias de Minas Gerais - FIEMG, pelo apoio financeiro concedido.

À Empresa Brasileira de Pesquisa Agropecuária EMBRAPA, pelo apoio pessoal.

\section{REFERÊNCIAS BIBLIOGRÁFICAS}

CLAIR. J. B. S. T.; KLEINSCHMIT, J.; SVOLBA, J. Juvenility and serial vegetative propagation in Norway spruce clones (Picea abies). Silvae Genetica, v. 34, n. 1, p. $422-448,1985$.

ELDRIDGE, K. et al. Eucalypt domestication and breeding. Oxford: Clarendon Press, 1994. p. 228-246.

FERNANDES, D. E. Estratégia de uso da mini e microestaquia na clonagem de Eucalyptus na Celulose NipoBrasileira S/A. In: XAVIER, A.; PIRES, I. E. (Coords.) Reunião da Comissão Técnica de Genética e melhoramento. 1999, Mogi Guaçu. Resumos... Mogi Guaçu: 1999. s.p.

GREENWOOD, M. S. Theoretical aspects of juvenility and maturation. In: DAVIES, T. D.; HAISSIG, B. E.; SANKHLA, N. Mass production technology for genetically improved fast growing forest tree species. Bordeaux, 1992. (Colloque AFOCEL IUFRO, Paris, 1992).

GREENWOOD, M. S.; HUTCHISON, K. W. Maturation as a developmental process. In: AHUJA, M. R.; LIBBY, W. J. Clonal forestry: genetics and biotecnology. Budapest: Springer-Verlag, 1993. p. 14-33.

R. Árvore, Viçosa-MG, v.27, n.5, p.611-618, 2003 
HACKETT, W. P.; MURRAY, J. R. Maturation and rejuvenation in woody species. In: AHUJA, M. R. Micropropagation of woody plants. Dordrecht: Kluwer Academic Publishers, 1993. p. 93-105.

HACKETT, W. P. Juvenility and maturity. In: CELL and tissue culture in forestry. Dordrecht: Keuwer Academic Publishers, 1987. p. 216-231.

HIGASHI, E. N.; SILVEIRA, R. L. V. A.; GONÇALVES, A. N. Nutrição e adubação em minijardim clonal hidropônico de Eucalyptus. Circular Técnica IPEF, n. 194, p. 1-21, 2002.

IKEMORI, Y. K. Resultados preliminares sobre enraizamento de estacas de Eucalyptus spp. Aracruz: 1975. 12 p. (Informativo Técnico Aracruz, 1).

PARKER, S. R. et al. The effects of scion maturation on growth and reproduction of grafted slash pine. New forest, v. 3 , n. 15 , p. $243-259,1998$.
SILVA, L. F. Propagação vegetativa de eucalipto: a experiência da International Paper do Brasil. IPEF Notícias, v. 25, n. 156, p. 1-3, 2001.

TITON, M. Propagação clonal de Eucalyptus grandis por miniestaquia e microestaquia. 2001. 65 f. Dissertação (Mestrado em Ciência Florestal) - Universidade Federal de Viçosa, Viçosa, 2001.

WENDLING, I. Propagação clonal de híbridos de Eucalyptus spp. por miniestaquia. 1999. $70 \mathrm{f}$.

Dissertação (Mestrado em Ciência Florestal) - Universidade Federal de Viçosa, Viçosa, 1999.

WENDLING, I. Miniestaquia e micropropagação seriada no rejuvenescimento de clones de Eucalyptus grandis. 2002. 94 f. Tese (Doutorado em Ciência Florestal) Universidades Federal de Viçosa, Viçosa, 2002.

ZOBEL, B.; TALBERT, J. Applied forest tree improvement. New York: North Carolina State University, 1984. $505 \mathrm{p}$. 